\title{
Reproductive wastage in the androstenedione-immune ewe
}

\author{
R. J. Scaramuzzi, C. D. Nancarrow, J. D. Murray* and J. R. Walton $\dagger$ \\ CSIRO Division of Animal Production, PO Box 239, Blacktown 2148, NSW, Australia
}

\begin{abstract}
An experiment was carried out using 320 adult Merino ewes to examine the effects of immunization against an androstenedione human serum albumin conjugate (Fecundin) on ovulation rate, fertilization rate and embryo viability at days 2,9 and 13-14 after fertilization. The ovulation rate of immunized ewes $(2.19 \pm 0.06)$ was greater $(P<0.001)$ than that of control ewes $(1.43 \pm 0.04)$. The recovery rate of embryos or of unfertilized oocytes on day 2 was reduced in immunized ewes, but fertilization rate of recovered oocytes was unaffected by immunization. The mean number of normal embryos per ewe pregnant (prolificacy) was higher and the proportion of ewes pregnant (fertility) was lower in immunized than in the control ewes. The distribution of the number of cells per embryo showed no differences in developmental age over the period of sampling, the majority of embryos at this time being at the two- to four-cell stage of development. At day 9 of pregnancy, blastocyst recovery rates were lower in immunized than in control ewes. About $90 \%$ of blastocysts recovered were developing normally in control ewes compared with $64 \%$ in immunized ewes. The majority of blastocysts recovered on day 9 had hatched from the zona pellucida prior to recovery (mean values were $94.2 \%$ and $87.8 \%$ for control and immunized groups, respectively). In control ewes single blastocysts were larger than twin blastocysts, but for the immunized ewes this difference was not significant. Both single blastocysts $(P<0.01)$ and twin blastocysts $(P<0.05)$ from immunized ewes were smaller than those from control ewes. By day 13-14 of pregnancy the blastocyst recovery rate, the percentage of blastocysts developing normally and the number of blastocysts per 100 corpora lutea were all significantly depressed in immunized compared with control ewes, but there were no differences between single and twin blastocysts in the size of the trophoblast or of the embryonic disc for either group. Blastocysts from immunized ewes were smaller than blastocysts of comparable ages from control ewes. The longest diameter of the trophoblast $(P<0.001)$, the diameter of the trophoblast at $90^{\circ}$ to the longest axis $(P<0.05)$ and the longest diameter of the embryonic disc $(P<0.001)$ were all reduced in embryos recovered from immunized compared with control ewes.
\end{abstract}

\section{Introduction}

The immunization of ewes with steroid-protein conjugates of androstenedione (Scaramuzzi and Hoskinson, 1984) leads to increases in ovulation rate and, under appropriately controlled conditions, to increases in lambing percentages (Scaramuzzi et al., 1983; Geldard et al., 1984; Philipon and Driancourt, 1987). The gain in lambing percentage is usually less than the corresponding gain in ovulation rate; this difference is almost entirely due to post-ovulatory reproductive wastage. In an earlier study we attempted to partition these reproductive losses in control and androstenedione-immune ewes by estimating reproductive performance at three times after mating (Boland et al., 1986). Two major sources of reproductive wastage were identified: the

Present addresses: *Department of Animal Science, University of California Davis, Davis, CA 95616, USA; † Department of Geriatrics, Concord Repatriation Hospital, PO Box 152 Concord 2137, NSW, Australia.

Revised manuscript received 20 December 1992. first appeared within three days of the onset of oestrus and the second appeared later, but before day 13. The first source of reproductive wastage, only present in androstenedione-immune ewes, was detected as a reduction in embryo recovery rate at day 2 after mating (Boland et al., 1986). The second major source of waste, which occurred in both untreated and immunized ewes, was detected as a reduced percentage of normal, expanded blastocysts recovered on day 13 of pregnancy. This wastage, occurring sometime between days 3 and 13 of pregnancy, was partitioned into a relatively constant chromosomal component of about 10\% (Murray et al., 1986b), and a variable non-chromosomal component. In the present work the timing and nature of this reproductive wastage was further investigated by estimating the size and appearance of embryos recovered on days 2,9 and 13-14 of pregnancy from Merino ewes immunized against androstenedione-7-HSA (Fecundin: Coopers, Pitman Moore, North Ryde, NSW). A preliminary report of this experiment has been published in abstract form (Nancarrow et al., 1985). 


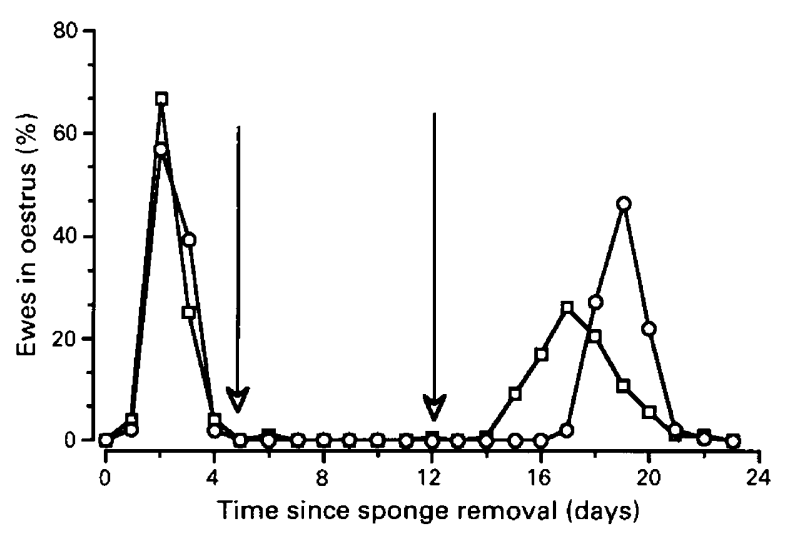

Fig. 1. The daily percentage distribution of ewes mating at first oestrus (days 1-5) and second oestrus (days 14-23) following the removal of progestagen-releasing pessaries in groups of Fecundin-treated $(\square$; $n=160)$ and untreated control $(O ; n=160)$ Merino ewes. The arrows indicate the time (day 5) at which the booster immunization was given and the time (day 12) at which fertile rams were introduced to the flock. Day zero is the day of removal of the progestagen pessaries.

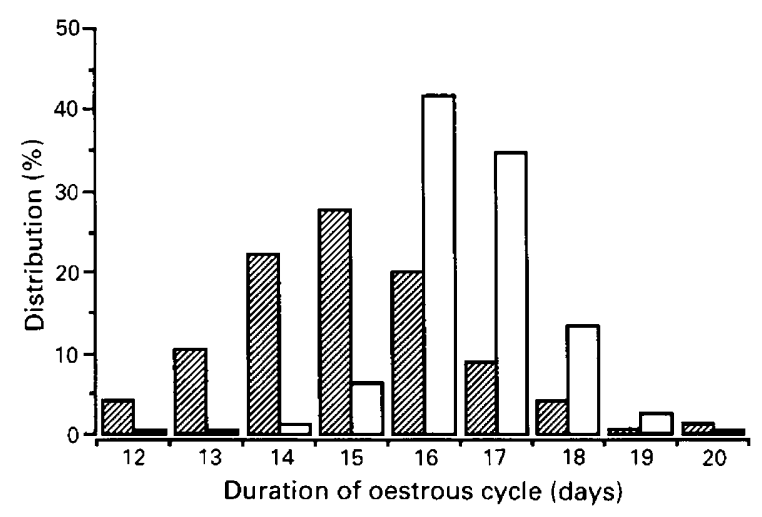

Fig. 2. The frequency distribution, expressed as a percentage, of the duration of the oestrous cycle in Fecundin-treated ( $\nabla ; n=160$ ) and untreated control ( $\square ; n=160$ ) Merino ewes. For untreated ewes the duration of the oestrous cycle was between 14 and 19 days (a spread of 6 days) and for immunized ewes its duration ranged between 12 and 23 days (a spread of 12 days). Note that the horizontal axis of the figure does not extend to 23 days.

\section{Materials and Methods}

\section{Animals and treatments}

Mature Merino ewes (320) were randomly allocated to two equal groups one of which was immunized against androstenedione $7 \alpha$-carboxyethylthioether-human serum albumin (Fecundin), whereas the other remained as an untreated control group. Twenty entire and 18 vasectomized Merino rams were used for mating and the detection of oestrus. Immunization comprised a primary injection followed four weeks later by an identical repeat (booster) immunization, each of $2 \mathrm{ml}$ injected subcutaneously behind the ear in the anterior third of the neck. Antibody titres to androstenedione were determined on samples of plasma obtained 7 days after booster immunization. Blood was collected by jugular venepuncture; the plasma was removed and stored frozen at $-20^{\circ} \mathrm{C}$. Antibody titres were also measured in 30 samples of uterine flushings collected on day 9 or days 13-14 of pregnancy. Antibody titres were determined by a radioligand binding method (Boland et al., 1986) and are reported as the dilution of serum that binds $50 \%$ of added ligand.

\section{Experimental procedure}

The experiment was conducted, during the mid-breeding season (March), as two identical replicates one week apart. Flock management and the mating programme were facilitated by using oestrous synchronization. Intravaginal sponges (Repromap: Upjohn Pty Ltd, Rydalmere, NSW) were inserted for 12 days and removed 5 days before the booster immunization. Fertile mating at the second oestrus, after removal of the progestagen pessaries, was timed to occur about 14 days after booster immunization, a time equivalent to that which produced the highest level of reproductive wastage in our earlier experiments (Boland et al, 1986). After removal of the pessaries, $15(10 \%)$ vasectomized Merino rams fitted with mating harnesses and coloured raddles (Sire-Sine: Hortico Australia Pty Ltd, NSW) were introduced to the flock which was then examined every $4 \mathrm{~h}$ for the presence of ewes in oestrus. These ewes were removed and, where necessary, oestrus was confirmed by direct observation of mating with one of a group of vasectomized rams kept aside for this purpose. Intensive testing for oestrus continued for $120 \mathrm{~h}$ after removal of the pessary and then inspections were made once a day. Twelve days after pessary removal the vasectomized rams were replaced by an equal number of fertile rams fitted with mating harnesses and coloured raddles. Daily observation for oestrus continued until the first ewe had mated at the second oestrus when testing recommenced every $4 \mathrm{~h}$. Testing continued until no ewes were detected in oestrus over three successive tests. Ewes were randomly allocated to one of three embryo recovery groups at the end of successive $24 \mathrm{~h}$ periods of oestrus detection.

\section{Embryo/blastocyst recovery}

Embryo/blastocyst recovery was attempted on day 2, day 9 and days 13-14 after mating. Embryos were recovered surgically, after Nembutal-induced anaesthesia $(480 \mathrm{mg})$, on day 2 between 09:00 h and 11:00 h or between 19:00 h and 21:00 h, the time chosen being that closest to $48 \mathrm{~h}$ after the first detection of oestrus. The oviduct was flushed with $5 \mathrm{ml}$ sodium phosphate and potassium phosphate buffered saline $(\mathrm{pH} 7.0$; $\left.0.01 \mathrm{~mol} \mathrm{I}^{-1}\right)$ containing $5 \%(\mathrm{v} / \mathrm{v})$ heat-treated sheep serum. On day 9 and days 13-14, the animals were anaesthetized by an intravenous injection of Nembutal $(480 \mathrm{mg})$ and the cervix, uterus, oviducts and ovaries removed. The ewes were then killed with more intravenous Nembutal $(1000 \mathrm{mg})$. The reproductive tract was chilled on ice and taken back to a laboratory, where each uterine horn was flushed with $15 \mathrm{ml}$ of the phosphate-buffered saline containing serum. The flushings were then searched for unfertilized oocytes and blastocysts. 
Table 1. Effect of androstenedione immunity in Merino ewes on the recovery and fertilization of oocytes recovered $48-74 \mathrm{~h}$ after mating and the estimated reproductive performance on day 2 of pregnancy (mean \pm SEM)

\begin{tabular}{lccc} 
Parameter & $\begin{array}{c}\text { Controls } \\
(n=52)\end{array}$ & $\begin{array}{c}\text { Immunized } \\
(n=50)\end{array}$ & $\begin{array}{c}\text { Difference due to } \\
\text { immunization }\end{array}$ \\
\hline $\begin{array}{l}\text { Number of ewes mated (\%) } \\
\text { Time of recovery (hours after oestrus) }\end{array}$ & $51(98)$ & $49(98)$ & 0 \\
Number of corpora lutea & $58.2 \pm 1.7$ & $61.4 \pm 1.2$ & Not applicable \\
(ovulation rate) & 72 & 98 & +0.68 \\
Number of oocytes recovered (\%) & $(1.41 \pm 0.08)$ & $(2.09 \pm 0.10)^{* *}$ & $(-16.2)$ \\
Number of oocytes fertilized (\%) & $66(91.7)$ & $64(75.5)^{* *}$ & $(-4.4)$ \\
Number of embryos per 100 corpora lutea & $60(90.9)$ & $65.3^{* *}$ & -18.0 \\
Number of fertilized oocytes per ewe pregnant & 83.3 & & +0.53 \\
Number of ewes with fertilized oocytes (\%) & & $1.78^{* * *}$ & -7.6 \\
Reproductive performance on day 2 of pregnancy & 1.25 & $36(86.5)^{*}$ & $1.31^{*}$ \\
\hline
\end{tabular}

'Per oocyte recovered.

bFertilized oocytes per ewe.

Significantly different from controls $\left({ }^{*} P<0.05 ;{ }^{* *} P<0.01 ;{ }^{* * *} P<0.001\right)$.

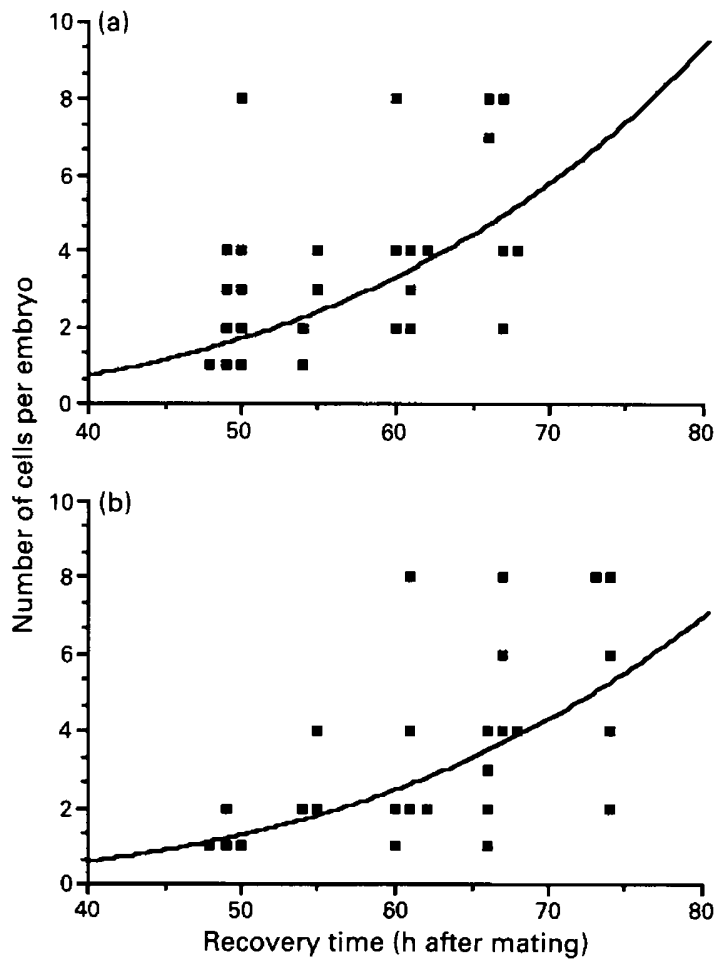

Fig. 3. The number of cells in early sheep embryos as a function of the time of embryo recovery in groups of (a) untreated control $(n=27)$ and (b) Fecundin-treated $(n=26)$ Merino ewes. Regression lines have been fitted to the data and have the following characteristics: control embryos $x=y^{3.566}$ and $R=0.70$; immune embryos $x=y^{3.619}$ and $R=0.77$, where $x$ is the age of the embryo in hours and $y$ is the number of cells in the embryo.

The ovulation rate at conception was recorded by counting the number of corpora lutea present on the ovaries at the time of embryo/blastocyst recovery. In the animals that were killed, the corpora lutea were dissected free and individually weighed to the nearest milligram.

\section{Measurement of embryos and blastocysts}

After measurement, all embryos were cultured in a solution of colchicine and processed for chromosome analysis (Murray et al., 1985, 1986a, b). The chromosome data from the day 2 embryos have been reported separately (Murray et al., 1988).

Day 2 embryos. The day 2 embryos were examined under low magnification $(\times 25)$ for fertilization and cleavage stage. All oocytes and one-cell embryos were examined further at a higher magnification $(\times 320)$ for the presence of spermatozoa in the zona pellucida and for the formation of pronuclei as evidence of fertilization having taken place.

Day 9 blastocysts. The day 9 blastocysts were examined under low magnification $(\times 25)$ and classified either as hatched from the zona pellucida, or as unhatched and remaining in the zona pellucida, or otherwise abnormal. The blastocysts were then measured using an ocular scale, by taking the length of the longest axis and a second measurement at $90^{\circ}$ to the long axis. Where necessary, further examination at a higher magnification was used to confirm initial findings. Numbers of unfertilized oocytes were also recorded.

Day 13-14 blastocysts. The day 13-14 blastocysts were examined and classified as normal or abnormal. Abnormal blastocysts were those that were markedly retarded in their stage of development or degenerating and fragmented. The total length of the normal expanded blastocysts was measured using an ocular scale, by taking the length of the longest axis and a second measurement at $90^{\circ}$ to the long axis. The diameter of the embryonic disc was also measured, using an ocular scale, in a random sample of 20 blastocysts from control and 20 
Table 2. The effect of androstenedione immunity in Merino ewes, on blastocyst development 9 days after mating, the weight of luteal tissue and the estimated reproductive performance on day 9 of pregnancy (mean \pm SEM)

\begin{tabular}{|c|c|c|c|}
\hline Parameter & $\begin{array}{l}\text { Controls } \\
(n=49)\end{array}$ & $\begin{array}{l}\text { Immunized } \\
\quad(n=46)\end{array}$ & $\begin{array}{l}\text { Difference due to } \\
\text { immunization }\end{array}$ \\
\hline Time of recovery (hours after oestrus) & $214.6 \pm 0.75$ & $216.0 \pm 2.1$ & Not applicable \\
\hline Number of corpora lutea & 72 & 104 & \\
\hline (ovulation rate) & $(1.47 \pm 0.14)$ & $(2.26 \pm 0.10)^{* * *}$ & +0.79 \\
\hline Number of oocytes or blastocysts recovered (\%) & $57(79.2)$ & $69(66.4)^{*}$ & $(-12.8)$ \\
\hline Number fertilized (\%) & $54(94.7)$ & $61(88.4)$ & $(-6.3)$ \\
\hline Number of blastocysts developing normally (\%) & $50(87.7)$ & $44(63.8)^{* * *}$ & $(-23.9)$ \\
\hline Number of blastocysts per 100 corpora lutea & 69.4 & $42.3^{* * *}$ & -27.1 \\
\hline Number of blastocysts per ewe pregnant & 1.14 & $1.47^{*}$ & +0.33 \\
\hline Number of ewes pregnant on day $9(\%)$ & $44(89.8)$ & $30(65.2)^{* *}$ & $(-24.6)$ \\
\hline
\end{tabular}

${ }^{2}$ Per oocyte or blastocyst recovered.

'Normal blastocysts per ewe.

Significantly different from controls $\left({ }^{*} P<0.05 ;{ }^{* *} P<0.01 ;{ }^{* *} P<0.001\right)$

Table 3. The long diameter (length in $\mu \mathrm{m}$ ), the diameter at $90^{\circ}$ to the long diameter (width in $\mu \mathrm{m}$ ) of blastocysts from day 9 of pregnancy in control ewes or ewes immune to androstenedione

\begin{tabular}{lccccc}
\hline & \multicolumn{2}{c}{ Control } & & \multicolumn{2}{c}{ Immunized } \\
\cline { 2 - 3 } \cline { 5 - 6 } Parameter & $\begin{array}{c}\text { Single } \\
(n=26)\end{array}$ & $\begin{array}{c}\text { Twin } \\
(n=26)\end{array}$ & & $\begin{array}{c}\text { Single } \\
(n=12)\end{array}$ & $\begin{array}{c}\text { Twin } \\
(n=29)^{\mathrm{a}}\end{array}$ \\
\hline Length $(\mu \mathrm{m})$ & $\begin{array}{c}281.8 \pm 17.1^{*} \\
(138-463)\end{array}$ & $\begin{array}{c}236.1 \pm 12.5 \\
(138-275)\end{array}$ & & $\begin{array}{c}192.8 \pm 16.9 \dagger \\
(125-350)\end{array}$ & $\begin{array}{c}207.1 \pm 10.5 \ddagger \\
(125-350)\end{array}$ \\
Width $(\mu \mathrm{m})$ & $\begin{array}{c}253.1 \pm 15.4^{* *} \\
(125-400)\end{array}$ & $\begin{array}{c}209.1 \pm 13.0 \\
(113-250)\end{array}$ & & $\begin{array}{c}160.1 \pm 14.5 \dagger \dagger \\
(113-250)\end{array}$ & $\begin{array}{c}172.9 \pm 8.2 \ddagger \ddagger \\
(100-275)\end{array}$ \\
\hline
\end{tabular}

\footnotetext{
Values are means \pm SEM with the range of values in parentheses.

aIncludes one set of triplet blastocysts.

${ }^{*} P=0.020$ (control singles versus control twins).

${ }^{* *} P=0.021$ (control singles versus control twins).

$\dagger P=0.00158$ (single immunized versus single control)

$\dagger \uparrow P=0.0398$ (single immunized versus single control).

$\ddagger P=0.00064$ (twin immunized versus twin control).

$\ddagger \ddagger P=0.0137$ (twin immunized versus twin control).
}

blastocysts from immunized ewes. Where necessary further examination at a higher magnification was used to confirm initial findings. Numbers of unfertilized oocytes were also recorded.

\section{Electron microscopy}

Six day 13-14 blastocysts from control ewes and six from Fecundin-treated ewes were selected at random and then prepared for scanning electron microscopy. They were fixed in $3 \%$ glutaraldehyde buffered at $\mathrm{pH} 7.3$ with 0.1 mol sodium cacodylate $1^{-1}$. Specimens were dehydrated in ascending concentrations of ethanol in water $(50 \%, 70 \%, 90 \%, 100 \%$ and $100 \%$ for a second time) before drying in a critical point drier (Polaron, Watford). Each specimen was mounted on a stub covered with double-sided adhesive tape $(3 \mathrm{M}$. Minneapolis, MI) and coated with gold in a Dynavac sputter-coater (Microvac, Sydney). Embryonic discs were examined on their inner and outer aspects and photographed in an ISI scanning electron microscope.

\section{Statistical analysis}

Data on ovulation rate, fertilization rate, the percentage of normal embryos or blastocysts and the recovery rates of 

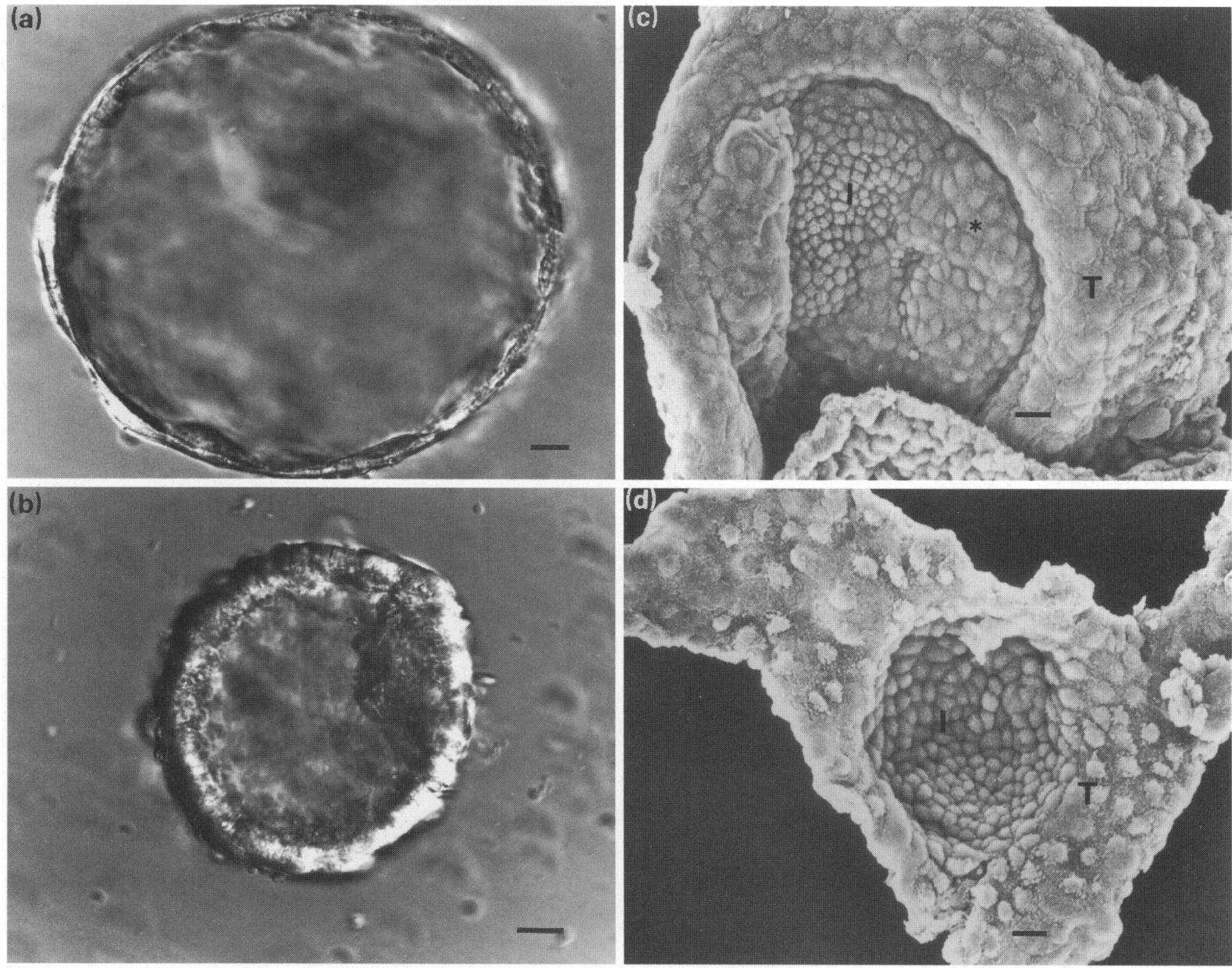

Fig. 4. (a) A day 9 blastocyst recovered from an untreated control Merino ewe. The blastocyst is $263 \mu \mathrm{m} \times 238 \mu \mathrm{m}$ (long diameter $\times$ diameter at $90^{\circ}$ to long diameter). The mean values ( \pm SEM) for the group are $260.3 \pm 11.2 \mu \mathrm{m} \times 232.0 \pm 10.5 \mu \mathrm{m}$. (b) A day 9 blastocyst from a Fecundin-treated Merino ewe. The blastocyst is $213 \mu \mathrm{m} \times 163 \mu \mathrm{m}$ in diameter. The mean values for the group are 203.1 $\pm 8.9 \mu \mathrm{m} \times 169.8 \pm 7.1 \mu \mathrm{m}$. (c) Scanning electron micrograph of the trophoblast (T), the inner cell mass (I) and the endoderm from an untreated control Merino ewe. Endodermal cells $\left(^{*}\right)$ can be seen partially spread over the ventral aspect of the embryonic disc. (d) Scanning electron micrograph of trophoblast and the inner cell mass from a Fecundin-treated Merino ewe. Endodermal cells are not yet visible on the ventral surface of the embryo. The bars represent $20 \mu \mathrm{m}$.

embryos or blastocysts at the three stages of pregnancy were analysed by $\chi^{2}$ test. Other data, if normally distributed, were analysed by unpaired $t$ test. Data not normally distributed were analysed by Wilcoxon rank sum test. Unless otherwise indicated in the text the unpaired $t$ test was used to test differences. Titre values were transformed to square roots before analysis.

\section{Results}

There were no significant differences between the two replicates and the data were pooled for re-analysis and presentation.

Oestrus was detected in $99 \%$ of control and $97 \%$ of treated ewes within 4 days of removal of intravaginal sponges. The distribution of the time of onset of oestrus (Fig. 1) shows that immunized ewes displayed oestrus at the same time as control ewes. At the second oestrus following pessary removal, $100 \%$ of control and $94 \%$ of immunized ewes mated between 12 and 23 days after sponge removal; immunized ewes mated $12.54 \pm 0.25$ days (mean \pm SEM) after their repeat immunization. The duration of the oestrous cycle (the inter-mating interval) for control ewes was $16.59 \pm 0.08$ days (mean \pm SEM) and this was significantly longer than for immunized ewes (15.25 \pm 0.19 days $P<0.05$ ). The time of the second oestrus was more variable in immunized ewes and was spread over 12 days compared with a spread of only 6 days for control ewes (Fig. 2).

The ovulation rate of immunized ewes $(2.19 \pm 0.06$; mean \pm SEM) was significantly greater $(P<0.001)$ than that of control ewes $(1.43 \pm 0.04)$. There was no effect of sampling time on estimates of ovulation rate. The mean untransformed reciprocal antibody titre, measured 7 days after repeat immunization, was $15877 \pm 1947$; there were no significant differences among the day 2, day 9 and day 13 sub-samples. The uterine flushings from immunized ewes contained minor quantities of antibody to androstenedione; the titres, although above the level of non-specific binding to the assay, were less than ten. 
Table 4. The effect of androstenedione immunity in Merino ewes on blastocyst development 13 days after mating, the weight of luteal tissue, and the estimated reproductive performance on day 13 of pregnancy (mean \pm SEM)

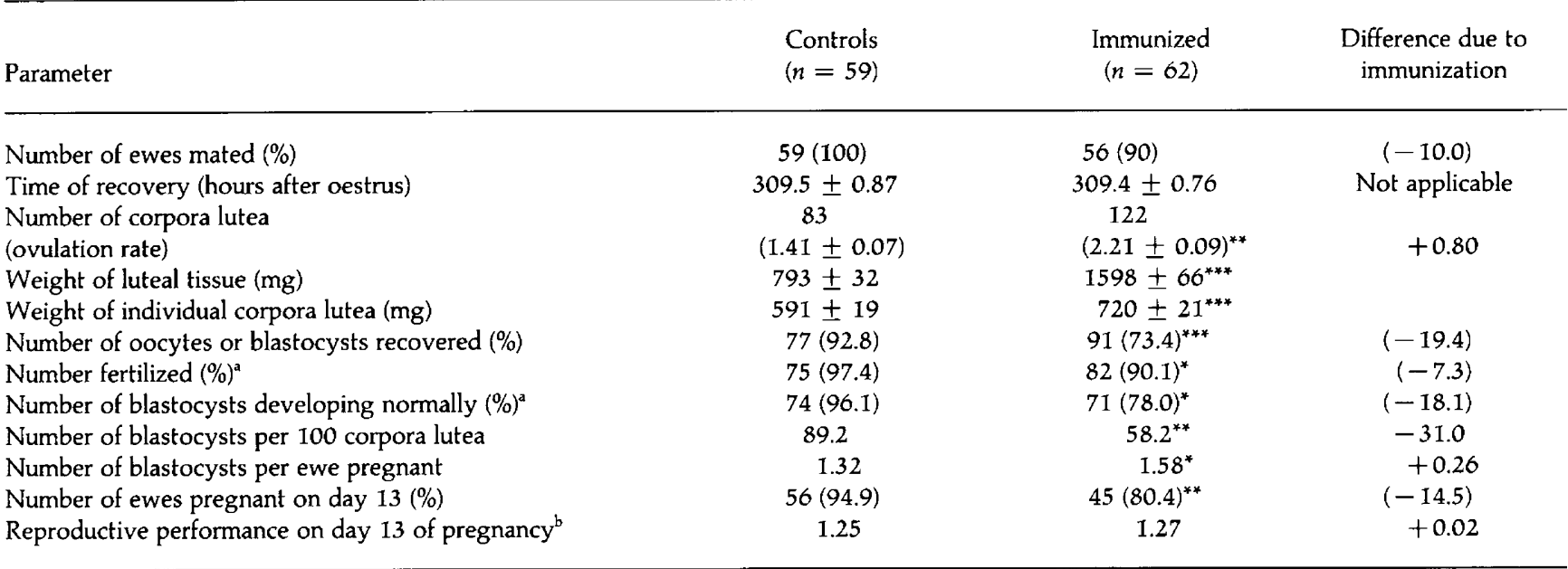

aPer oocyte or blastocyst recovered.

Normal blastocysts per ewe.

Significantly different from controls $\left({ }^{*} P<0.05 ;{ }^{* *} P<0.01 ;{ }^{* *} P<0.001\right)$

Table 5. The long diameter (length in $\mathrm{mm}$ ), the diameter at $90^{\circ}$ to the long diameter (width in $\mathrm{mm}$ ) of the trophoblast of expanded blastocysts and the long diameter of the embryonic disc (diameter in $\mu \mathrm{m}$ ) from sheep blastocysts collected on day 13 of pregnancy in untreated (control) ewes or ewes immune to androstenedione

\begin{tabular}{|c|c|c|c|c|}
\hline \multirow[b]{2}{*}{ Parameter } & \multicolumn{2}{|c|}{$\begin{array}{l}\text { Control } \\
(n=40)\end{array}$} & \multicolumn{2}{|c|}{$\begin{array}{l}\text { Immunized } \\
(n=45)\end{array}$} \\
\hline & Single & Twin & Single & Twin \\
\hline Length $(\mathrm{mm}) \dagger$ & $\begin{array}{l}8.46 \pm 2.67^{*} \\
(0.76-79.00)\end{array}$ & $\begin{array}{l}3.79 \pm 0.71 \\
(0.46-18.20)\end{array}$ & $\begin{array}{l}3.07 \pm 1.66 \\
(0.36-32.00)\end{array}$ & $\begin{array}{l}2.84 \pm 0.82 \\
(0.21-37.00)\end{array}$ \\
\hline Width $(\mathrm{mm}))^{\dagger} \dagger$ & $\begin{array}{c}0.99 \pm 0.06 \\
(0.29-2.22)\end{array}$ & $\begin{array}{c}0.94 \pm 0.07 \\
(0.35-2.70)\end{array}$ & $\begin{array}{c}0.78 \pm 0.09 \\
(0.28-1.69)\end{array}$ & $\begin{array}{c}0.86 \pm 0.06 \\
(0.20-1.91)\end{array}$ \\
\hline $\begin{array}{l}\text { Diameter of } \\
\text { embryonic disc }(\mu \mathrm{m}) \dagger+\dagger\end{array}$ & $\begin{array}{l}354 \pm 35^{* *} \\
(139-1250)\end{array}$ & $\begin{array}{l}307 \pm 19 \\
(125-554)\end{array}$ & $\begin{array}{l}247 \pm 53 \\
(88-880)\end{array}$ & $\begin{array}{l}249 \pm 21 \\
(100-678)\end{array}$ \\
\hline
\end{tabular}

\footnotetext{
${ }^{*} P=0.0635$ (control singles versus control twins).

${ }^{* *} P=0.021$ (control singles versus control twins).

$\dagger P=0.00001$ (all immunized versus all control).

$+\uparrow P=0.0357$ (all immunized versus all control).

$++P=0.00002$ (all immunized versus all control).
}

Values are means \pm SEM with the range of values in parentheses.

\section{Embryo survival and development by day 2 of pregnancy}

The average time of collection of embryos was not different for the two groups of ewes (Table 1) and the distribution of the number of cells per embryo (Fig. 3) shows no difference in developmental age over the period of sampling; the majority of embryos at this time were at the two- to four-cell stage of development. The recovery rate of fertilized and unfertilized oocytes was reduced in immunized ewes but the fertilization rate of those recovered was unaffected by immunization (Table 1). Hence the percentage of corpora lutea represented as fertilized oocytes on day 2 of pregnancy was reduced from $83 \%$ in control ewes to $65 \%$ in immunized ewes. The average number of normal embryos per ewe pregnant (a measure of prolificacy) was higher and the proportion of ewes pregnant (a measure of fertility) was lower in immunized ewes (Table 1 ). The net result was a significant increase, on day 2 of pregnancy, in the potential reproductive performance of treated ewes (average number of fertilized oocytes per ewe).

\section{Embryo survival and blastocyst development by day 9 of pregnancy}

By day 9 of pregnancy, blastocyst recovery rates remained lower in immunized ewes, both groups having decreased by 
about $10 \%$ from recovery rates on day 2 (Table 2). About $90 \%$ of blastocysts recovered were developing normally in control ewes and this figure was significantly lower $(64 \%)$ for immunized ewes (Table 2). The effect of this high incidence of abnormal blastocyst development, seen as a reduction in the number of blastocysts per 100 corpora lutea, is to eliminate the potential gains in reproductive performance, due to Fecundin treatment, that were observed at day 2 (compare Tables 1 and 2).

The ovaries of immunized ewes contained significantly more luteal tissue than those from control ewes, but the weight of the individual corpora lutea did not differ between the groups (Table 2).

The majority of blastocysts recovered on day 9 had hatched from the zona pellucida prior to recovery $(94.2 \%$ and $87.8 \%$ for control and immunized groups, respectively). For control ewes, single blastocysts were significantly larger than twin blastocysts (Table 3), but for the immunized ewes this difference was not significant. Single blastocysts and twin blastocysts from immunized ewes were significantly smaller than those from control ewes (Table 3). Day 9 blastocysts from an immunized ewe and a control ewe, chosen to be as close to the mean size of day 9 blastocysts from their respective treatment group are shown (Fig. 4a, b).

\section{Blastocyst survival and development by day 13 of pregnancy}

On day 13 of pregnancy the estimates of reproductive performance were similar to those on day 9 (Table 4). The blastocyst recovery rate, the percentage developing normally and the number of blastocysts per 100 corpora lutea were all significantly depressed in immunized ewes. A drop in fertility was offset to some extent by a small gain in prolificacy resulting in a similar potential reproductive performance in both groups of ewes.

In contrast to ovaries recovered on day 9 of pregnancy, those recovered from immunized ewes on day 13 or 14 contained twice as much luteal tissue as those recovered from control ewes. The weight of the individual corpora lutea from immunized ewes was significantly greater (Table 4).

There were no significant differences between single and twin blastocysts in size of the trophoblast or of the embryonic disc for either group (Table 5). Single and twin blastocysts were therefore pooled for further analysis. Blastocysts from immunized ewes were smaller than blastocysts of comparable age from control ewes. The long diameter of trophoblast (Wilcoxon test), the diameter of trophoblast at $90^{\circ}$ to the long axis and the long diameter of the embryonic disc (Wilcoxon test) were significantly reduced in embryos from immunized ewes.

The embryonic discs from immunized and control ewes appeared similar on their dorsal aspect, but ventrally, and in cross-section, all of the embryos from control ewes showed evidence of the endoderm leaving the inner cell mass and spreading out over the ventral surface of the trophectoderm. All but one of the embryos from the Fecundin-treated ewes were still at the inner cell mass stage prior to endoderm formation (Fig. 4c, d). Endodermal cells appeared slightly larger than ectodermal cells in the electron micrographs, because the endodermal cells are more flattened when viewed from this aspect.

\section{Discussion}

In our control ewes, the level of embryonic wastage observed in this experiment was within the normal range reported (Edey, 1969; Wilmut et al., 1985a). There was a loss of between 2.6 and $9.1 \%$ arising from the failure of fertilization and an additional loss of between 1.3 and $7.0 \%$ before day 13 of pregnancy. Most of this loss is probably associated with the presence of abnormal chromosomes (Murray et al., 1986b).

The results presented in this paper confirm and extend our earlier findings (Boland et al., 1986) that Merino ewes immunized against androstenedione suffer from increased levels of early embryonic wastage if they are mated too soon after receiving their repeat (booster) immunization. The optimum time for mating is from 21 to 35 days after a repeat immunization (Geldard et al, 1984) and in this experiment a mating system was selected, with a 13-14 day interval, that would produce a high level of embryonic death and facilitate our objectives. The recovery rate of oocytes on day 2 was reduced by immunization, confirming our earlier findings (Boland et al., 1986) but shedding no further light on the reason(s). Because the embryo recovery rate was reduced in immunized ewes at all stages of pregnancy considered, regardless of the method used to recover the embryos, we consider that the lower recovery rate in immunized ewes is not an artefact.

The estimate, on day 2 , of reproductive wastage due to immunization (18.0 embryos per 100 corpora lutea) can be almost entirely accounted for by the reduction in embryo recovery rate (16.2 embryos per 100 corpora lutea). The positive identification of corpora lutea at endoscopy requires, amongst other criteria, that an ovulation point is clearly identified on each corpus luteum. It can therefore be assumed that ovulation has taken place and that a significant proportion of the corpora lutea in immunized ewes release oocytes that do not find their way into the oviducts. The further definition of the nature of this reproductive wastage in immunized ewes requires additional experimentation.

A high level of reproductive wastage, due to immunization with Fecundin, was also observed on day 9 (26.1 blastocysts per 100 corpora lutea) and on day 13 or 14 (31.0 blastocysts per 100 corpora lutea) of pregnancy. These losses confirm our previous work (Boland et al, 1986), in which a decrease of 36 blastocysts per 100 corpora lutea was reported on day 13 , and 28 blastocysts per 100 corpora lutea for between days 24 and 32 of pregnancy. These losses cannot be accounted for by the reduction of blastocyst recovery rate alone (12.8 blastocysts per 100 corpora lutea). This difference indicates that there is a second major source of reproductive wastage in immunized ewes occurring sometime between days 2 and 9 of pregnancy that appears to be associated with abnormal blastocyst development in the immunized ewes. The estimates for the extent of this later loss are similar on days 9 and 13 (13.3 and 11.6 blastocysts per 100 corpora lutea, respectively) of pregnancy and suggest that no additional embryonic wastage occurs between these times. Likewise, our earlier work shows no additional wastage between days 13 and 24 to 32 after mating (Boland et al., 1986). This evidence suggests that there is no interference with the anti-luteolytic mechanism, as a result of immunization against androstenedione, despite the reduced size of the conceptus and the altered steroid milieu of immunized ewes. 
The potential reproductive performance was estimated, at three stages of pregnancy, as the number of normal embryos or blastocysts per ewe. These data show a reduced reproductive performance on day 9 compared with that on day 13. This inconsistency could be an artefact caused by underestimation of the normality and viability of embryos collected on day 9. The assessments of normality are subjective and day 9 embryos have an irregular and granulated appearance and consequently could easily be confused with degenerating embryos.

The oestrous cycle was shorter in Fecundin-treated than in control ewes, confirming our earlier suggestion (Boland et al., 1986) of an effect that was associated with the premature release of uterine $\mathrm{PGF}_{2 \alpha}$. The synthesis and release of a luteolytic dose of uterine $\mathrm{PGF}_{2 \alpha}$ requires the prior exposure of the endometrium to luteal phase concentrations of progesterone for about 12 days (Baird, 1978; Scaramuzzi et al., 1977). Postovulatory luteal function in Fecundin-treated ewes appears to be established 1-2 days sooner than in control ewes (Scaramuzzi et al., 1988), as circulating progesterone concentrations reached I $\mathrm{ng} \mathrm{ml}^{-1}$ by 2 days after the onset of oestrus compared with 4 days in untreated ewes. This advancement in the establishment of luteal function may explain the reduced duration of the oestrous cycle observed in this experiment (Lawson and Cahill, 1983).

The earlier establishment of luteal function might also have important effects on embryo growth and development and on the probability of embryo survival (Miller and Moore, 1976). The effect produced by immunization may be compared with the effect of asynchronous embryo transfer on embryo survival (Wilmut et al., 1985a, b; 1986). The hormonal milieu must be closely matched (to within $24 \mathrm{~h}$ ) to the developing blastocyst to ensure normal development (Wilmut and Sales, 1981). The rapid increase in progesterone concentrations in immunized ewes may then result in asynchrony between progesterone concentrations, uterine function and the development of the blastocyst (Lawson et al., 1983). Embryo development and survival is also influenced by oestradiol concentrations. Consequently, changes in the pattern of secretion or metabolism of this hormone may also influence embryo development and survival. In a study by Campbell et al. (1990), ewes immunized with Fecundin were shown to have increased secretion of progesterone and decreased secretion of oestradiol. In addition, the presence of increased plasma binding activity for both progesterone and oestradiol was also detected in Fecundin-treated ewes. The importance of these findings for embryo development and survival remains to be established.

The authors acknowledge the expert technical assistance of $\mathrm{A}$. Dafter, J. Downing, I. Hazelton, K. Lewis, J. Marshall and S. Shipp.

\section{References}

Baird DT (1978) Local utero-ovarian relationships. In Control of Ovulation pp 217-233 Eds DB Crighton, GR Foxcroft, NB Haynes and GE Lamming. Butterworths, London
Boland MP, Nancarrow CD, Murray JD, Scaramuzzi RJ, Sutton R, Hoskinson RM and Hazelton IG (1986) Fertilization and early embryonic development in androstenedione-immune Merino ewes Journal of Reproduction and Fertility 78 423-431

Campbell BK, Scaramuzzi RJ, Downing JA and Evans G (1990) Steroid secretion rates and plasma binding activity in ewes with an ovarian autotransplant actively immunized against androstenedione Joumal of Reproduction and Fertility $89485-496$

Edey TN (1969) Prenatal mortality in sheep: a review Animal Breeding Abstracts $37173-190$

Geldard H, Scaramuzzi RJ and Wilkins JF (1984) Immunization against polyandroalbumin leads to increases in lambing and tailing percentages New Zealand Veterinary Joumal 32 2-5

Lawson RAS and Cahill LP (1983) Modification of the embryo-maternal relationship in ewes by progesterone treatment early in the oestrous cycle Joumal of Reproduction and Fertility 67 473-475

Lawson RAS, Parr RA and Cahill LP (1983) Evidence for maternal control of blastocyst growth after asynchronous transfer of embryos to the uterus of the ewe Joumal of Reproduction and Fertility 67 477-483

Miller BG and Moore NW (1976) Effect of progesterone and oestradiol on RNA and protein metabolism in the genital tract and on survival of embryos in the ovariectomized ewe Australian Joumal of Biological Sciences 29 565-573

Murray JD, Boland MP, Moran C, Sutton R, Nancarrow CD, Scaramuzzi RJ and Hoskinson RM (1985) Occurrence of haploid and haploid-diploid mosaic embryos in untreated and androstenedione-immune Australian Merino sheep Joumal of Reproduction and Fertility 74 551-555

Murray JD, Boland MP and Moran C (1986a) Frequency of chromosomal abnormalities in embryos from superovulated Merino ewes Journal of Reproduction and Fertility 78 433-437

Murray JD, Moran C, Boland MP, Nancarrow CD, Sutton R, Hoskinson RM and Scaramuzzi RJ (1986b) Polyploid cells in blastocysts and early fetuses from Australian Merino sheep Journal of Reproduction and Fertility $\mathbf{7 8}$ 439-446

Murray ID, Nancarrow CD, Scaramuzzi RJ and Cognié Y (1988) Polyploid abnormalities in day 3 and day 5 Merino sheep embryos Australian Journal of Biological Sciences 41 157-161

Nancarrow CD, Murray JD, Scaramuzzi RJ, Marshall JT, Hazelton IH, Hoskinson RM and Boland MP (1985) Fertilization and embryo development in androstenedione-immune sheep Proceedings of the Australian Society for Reproductive Biology 176

Philipon P and Driancourt MA (1987) Potential of active immunization against androstenedione to improve fecundity in sheep Animal Reproduction Science 15 101-112

Scaramuzzi RJ and Hoskinson RM (1984) Active immunization against steroid hormones for increasing fecundity. In Immunological Aspects of Reproduction in Mammals pp 445-474 Ed. DB Crighton, Butterworths, London

Scaramuzzi RJ, Baird DT, Boyle HP, Land RB and Wheeler AG (1977) The secretion of prostaglandin $F$ from the autotransplanted uterus of the ewe Journal of Reproduction and Fertility 49 157-160

Scaramuzzi RJ, Geldard H, Beels CM, Hoskinson RM and Cox RI (1983) Increased lambing percentages through immunization against steroid hormones Wool Technology and Sheep Breeding 31 87-97

Scaramuzzi RJ, Downing JA, Campbell BK and Cognié Y (1988) Control of fertility and fecundity of sheep by means of hormonal stimulation Australian Journal of Biological Sciences 41 37-45

Wilmut I and Sales DI (1981) Effect of an asynchronous environment on embryonic development in sheep Journal of Reproduction and Fertility 61 179-184

Wilmut I, Sales DI and Ashworth CJ (1985a) Physiological criteria for embryo mortality: is asynchrony between embryo and ewe a significant factor? In Genetics of Reproduction in Sheep pp 275-289 Eds RB Land and DW Robinson. Butterworths, London

Wilmut I, Sales DI and Ashworth CJ (1985b) The influence of variation in embryo stage and maternal hormone profiles on embryo survival in farm animals Theriogenology 23 107-119

Wilmut I, Sales DI and Ashworth CJ (1986) Matemal and embryonic factors associated with prenatal loss in mammals Journal of Reproduction and Fertility $76851-864$ 